\title{
Ethical and Legal Issues in the Use of Online-Based Health Services (E-Health)
}

Issue Etik dan Hukum dalam Penggunaan Layanan Kesehatan Berbasis Online (E-Health)

\author{
Fitriani Nur Damayanti; Absori; Kelik Wardiono; Sri Rejeki \\ email: fitriani@unimus.ac.id \\ DIII Midwifery Study Program Faculty of Nursing and Health \\ Muhammadiyah University of Semarang
}

\begin{abstract}
The internet offers unprecedented power to provide users with health information for patients, health professionals, and professionals. Maintaining the integrity, data systems, and confidentiality of individual health information, quality of content, and consumer protection and the commercial interests of the health industry against unethical practices, are areas of greatest concern in the implementation and use of the Internet. However, there is no national and international legislation for regulating the use of online-based health services. This research is a Literature review that aims to explore ethical and legal issues in the use of onlinebased health services (E-Health). The review process begins by identifying journal articles that are relevant to the research topic. This study concludes that the use of online-based health services (E-Health) is an important public health issue. E-Health emerged as a tool for developing new diagnostics and therapeutic interventions. Ethical issues related to crossing clinical practice and online communication about health services. This allows discriminatory or unethical behavior and is not following the professional code of ethics. E-Health licensing standards and regulations have not been implemented in many countries. So that health workers are required to code of ethics in the use of online-based health services (E-Health).
\end{abstract}

Keywords: Ethical Issues, Health Services, Online-Based, E-Health

Abstrak: Internet menawarkan kekuatan yang belum pernah ada sebelumnya untuk menyediakan pengguna informasi kesehatan bagi pasien, tenaga kesehatan dan profesional. Menjaga integritas, sistem data, dan kerahasiaan informasi kesehatan individu, kualitas isi, dan perlindungan konsumen dan kepentingan komersial industri kesehatan terhadap praktik-praktik yang tidak etis, adalah bidang yang menjadi perhatian terbesar dalam implementasi dan penggunaan Internet. Namun belum ada legislasi nasional dan internasional untuk pengaturan tentang penggunaan layanan kesehatan berbasis online.

Penelitian ini merupakan Literature review yang bertujuan untuk mengeksplorasi issue etik dan hukum dalam penggunaan layanan kesehatan berbasis online (E-Health). Proses review dimulai dengan mengidentifikasi jurnal artikel yang relevan dengan topik penelitian.

Simpulan penelitian ini bahwa penggunaan layanan kesehatan berbasis online (E-Health) adalah masalah kesehatan masyarakat yang penting. E-Health muncul sebagai alat pengembangan diagnostik baru dan intervensi terapeutik. Adanya masalah etika yang berkaitan dengan persimpangan praktik klinik dan komunikasi online tentang pelayanan kesehatan. Hal ini memungkinkan adanya perilaku diskriminatif atau tidak etis serta tidak sesuai dengan kode etik profesi. Standar lisensi dan regulasi E-Health belum dilakukan di 
SOEPRA Jurnal Hukum Kesehatan

TERAKREDITASI RISTEKDIKTI Peringkat 4

ISSN:2548-818X (media online) Vol. 6 (1) Juni 2020

banyak negara. Sehingga tenaga kesehatan dituntut untuk kode etik dalam penggunaan layanan kesehatan berbasis online (E-Health).

Kata Kunci: Issue Etik, Layanan Kesehatan, Berbasis Online, E-Health

\section{PENDAHULUAN}

Internet telah berhasil mengubah tren konvensional pelayanan kesehatan di berbagai macam tempat di belahan dunia. Pasien yang sebelumnya hanya dapat berkonsultasi dengan dokter di tempat praktik, kini memiliki kemudahan untuk mendapatkan pelayanan kesehatan. Internet memungkin pasien tanpa harus bertatap muka dengan dokter. Selaras dengan praktik layanan kesehatan umum yang mengedepankan adanya kode etik pelayanan kesehatan, layanan kesehatan berbasis internet harus pula memiliki kode etik tersendiri (Amelia, 2016).

Internet menawarkan kekuatan yang belum pernah ada sebelumnya untuk menyediakan pengguna informasi kesehatan bagi pasien, tenaga kesehatan dan profesional dengan ketepatan waktu, akurasi, dan keragaman yang belum pernah terjadi sebelumnya. Kualitas yang menjadikan Internet sebagai pasar ide yang kaya - strukturnya yang terdesentralisasi, jangkauan global, pemerataan akses ke alat-alat publikasi, dan kemampuan untuk memfasilitasi pertukaran dengan jangkauan yang luas juga dapat memberikan potensi informasi yang salah, penggunaan yang tidak etis, praktik mandiri yang curang, praktik penipuan, dan penghindaran regulasi yang sah (Stanberry, 1998).

Ada banyak kekurangan terkait legislasi nasional dan internasional terutama mengenai masalah yurisdiksi dan kebijakan yang membahas hak dasar dan tanggung jawab pengguna dan penyedia layanan kesehatan berbasis online. Kebebasan akses ke informasi serta perlindungan keamanan data dan privasi pengguna adalah topik yang sangat penting. Keputusan yang terkait dengan masalah hukum dunia maya dan masalah etika di bidang kesehatan dan perawatan kesehatan harus melibatkan para pakar dari berbagai bidang pengetahuan yang melibatkan hukum perdata dan pidana, etika kedokteran, etika medis, standar profesi tenaga kesehatan (Mendel, 1999).

Menjaga integritas, sistem data, dan kerahasiaan informasi kesehatan individu, kualitas isi, dan perlindungan konsumen dan kepentingan komersial industri kesehatan terhadap praktik-praktik yang tidak etis, adalah bidang yang menjadi perhatian terbesar dalam implementasi dan penggunaan Internet dan aplikasi interaktif lainnya di bidang kesehatan dan pelayanan kesehatan (A. Smith and M. Anderson, 2018).

Privasi melibatkan banyak aspek dan masalah ini secara konsisten menjadi salah satu perhatian utama pengguna. Munculnya data kesehatan telah menimbulkan kekhawatiran terkait privasi, hak akses, dan tujuan penggunaan data pribadi. Di banyak negara reformasi undang-undang sebenarnya telah diberlakukan. Individu berhak untuk mengetahui informasi apa yang disimpan tentang mereka, siapa yang mengakses informasi itu, dan mekanisme apa yang tersedia untuk memperbaiki informasi yang salah (US Department of Health and Human Services, 1999).

Keaslian, keandalan, dan keakuratan informasi terkait kesehatan yang tersedia di situs kesehatan adalah masalah utama. Banyak situs web yang digerakkan oleh laba, yang lain mempromosikan bentuk perawatan atau produk yang tidak terbukti dan bahkan berbahaya, 
sementara yang lain mungkin mengandung informasi yang menyesatkan atau salah. Untuk memastikan kredibilitas, motif, sponsor, dan konflik kepentingan situs web adalah tugas yang sangat sulit. Di tengah-tengah "bebas-untuk-semua" ini, para dokter semakin dihadapkan dengan pasien yang mengerti internet datang ke konsultasi dengan tumpukan bahan yang siap di diskusikan (C. De Jong, 2015).

Media sosial memunculkan tantangan tersendiri. Mengingat pengaruh dari media sosial dan bukti yang muncul tentang pengaruhnya terhadap perilaku dan kesehatan manusia, ahli bioetika memiliki peran penting dalam pengembangan standar perilaku profesional bagi para profesional kesehatan yang menggunakan media sosial dan dalam desain sistem online sendiri. Media sosial adalah masalah bioetika yang memiliki implikasi serius bagi praktik medis, penelitian, dan kesehatan masyarakat (R. Volpe, 2013).

\section{RUMUSAN MASALAH}

Bagaimanakah issue etik dan hukum dalam penggunaan layanan kesehatan berbasis online (E-Health)?

\section{METODE PENELITIAN}

Penelitian ini merupakan Literature review yang bertujuan untuk mengeksplorasi issue etik dan hukum dalam penggunaan layanan kesehatan berbasis online (E-Health). Proses review dimulai dengan mengidentifikasi jurnal artikel yang relevan dengan topik penelitian. Artikel yang akan direview dalam penelitian ini mencakup penelitian kualitatif maupun kuantitatif tentang penggunaan layanan kesehatan berbasis online (E-Health). Artikel memuat hasil penelitian dari negara-negara yang telah menggunakan layanan kesehatan berbasis online ( $E$ Health).

\section{PEMBAHASAN}

1. Issue Etik yang Berkaitan Dengan Penggunaan Layanan Kesehatan Berbasis Online (EHealth)

Teknologi cenderung digambarkan sebagai revolusioner, tetapi penelitian menunjukkan teknologi hanya memproduksi dinamika sosial yang ada. Meskipun menimbulkan masalah bagi masyarakat tetapi membutuhkan solusi untuk pengembangan teknologi yang baik (G. C. Bowker, 2010).

Penggunaan layanan kesehatan berbasis online (E-Health) memiliki potensi untuk menambah atau mengurangi permasalahan yang ada. Di satu sisi, berisiko memperburuk ketidaksetaraan jika keputusan implementasi didorong oleh tujuan penghematan biaya daripada memperluas akses pelayanan kesehatan. Di sisi lain, pelayanan kesehatan online (E-Health) dapat memfasilitasi komunikasi yang lebih sering dengan profesional medis dalam pengaturan di mana individu mungkin tidak memiliki akses ke pelayanan kesehatan (Clark, Capuzzi, and Harrison, 2016). Karena alasan ini, banyak yang berpendapat bahwa pelayanan kesehatan berbasis online (E-Health) menawarkan manfaat besar terkait dengan akses terhadap pelayanan kesehatan (R. Martinson, 2013).

Konsekuensi dari E-Health dalam fasilitas pelayanan kesehatan, misalnya salah satu area yang memerlukan perhatian dari tenaga kesehatan. Fasilitas menggunakan E-Health sebagai alternatif biaya lebih rendah untuk kunjungan tatap muka dengan tenaga 
kesehatan (L. Kvasny, 2006). Pemahaman tentang pelayanan kesehatan sebagai hak dari individu yang memerlukan pemeriksaan lebih lanjut oleh tenaga kesehatan (A. D. Reich, 2014).

Kepercayaan tentang teknologi informasi sering membatasi masyarakat dalam pelayanan kesehatan secara online serta dapat menimbulkan konflik langsung dengan standar profesi (M. Simon, 2009).

Pergeseran antara hubungan pasien dengan dokter sering dimediasi oleh alat-alat digital sebagai aktor utama dalam proses pemberian layanan kesehatan (E. W. Kluge, 2017). Prinsip etika harus terpenuhi, diimplementasikan, dan digunakan dalam E-Health. Bidang etika medis ketika memberikan layanan kesehatan berbasis online harus berusaha untuk berkolaborasi dengan bidang-bidang seperti komputer dan informatika pelayanan kesehatan untuk mendorong penggabungan prinsip-prinsip etika ke dalam teknologi online (K. Yeung, 2017).

Penyedia layanan kesehatan harus memastikan bahwa teknologi medis dirancang dengan mempertimbangkan kebutuhan khusus pasien, seperti konsultasi melalui video yang digunakan di pedesaan. Penelitian menunjukkan bahwa pasien usia lanjut dapat mengambil manfaat dari E-Health untuk menghemat waktu perjalanan yang diperlukan dalam pelayanan kesehatan (B. Grady, 2011).

Pelayanan tenaga kesehatan kepada pasien dalam E-Health memungkinkan perilaku diskriminatif atau tidak etis. Misalnya konselor cenderung tidak merespons pesan langsung dari calon pasien jika individu tersebut tampak berkulit hitam dan kurang berpendidikan ( $\mathrm{H}$. Kugelmass, 2018). Dalam mengidentifikasi pelayanan kesehatan berbasis online yang tidak memiliki kesetaraan dalam akses bagi populasi yang terpinggirkan. Sebagai tenaga kesehatan harus mengadvokasi pemberian layanan kesehatan online yang dirancang dengan perhatian khusus pada kebutuhan beragam pasien (D. S. Char, 2018).

Penggunaan layanan kesehatan berbasis online (E-Health) adalah masalah kesehatan masyarakat yang penting. E-Health telah muncul sebagai alat pengembangan diagnostik baru dan intervensi terapeutik, tetapi juga sebagai katalisator perubahan sosial yang dapat berdampak buruk bagi kesehatan masyarakat (D. J. Burgess, 2016). Oleh karena itu, diperlukan cara untuk memahami terkait dengan praktik klinis dan standar etik agar tidak menimbulkan risiko kesehatan bagi pengguna (C. A. Maher, 2014).

Tenaga kesehatan memeriksa masalah etika yang berkaitan dengan persimpangan praktik klinik dan komunikasi online tentang kesehatan masyarakat dan kehidupan publik. Penggunaan layanan online (E-Health) dalam bidang pelayanan kesehatan akan menimbulkan permasalahan selama bertahun-tahun yang akan datang ( $M$. Ananny, K. Crawford, 2018).

Efek media sosial pada kesehatan individu dan populasi sangat luas dan bisa dibilang lebih cepat dan jauh jangkauannya daripada beberapa perkembangan penting dalam ilmu kedokteran (Eubanks, 2007). Sekarang saatnya tenaga kesehatan bersama dengan lembaga penelitian dan penyandang dana swasta, untuk berkomitmen untuk meneliti implikasi etis, hukum, dan sosial dari revolusi media sosial (Lupton and Maslen, 2011). 


\section{Regulasi Penggunaan Layanan Kesehatan Berbasis Online}

Standar lisensi dan regulasi E-Health belum dilakukan di banyak negara pada tingkat regional atau negara bagian. Lisensi profesional, alternatif dan praktik kesehatan yang tidak disetujui, bertentangan dengan praktik penipuan dan klaim menyesatkan, regulasi, dan masalah yurisdiksi hukum secara nasional dan internasional adalah masalah regulasi dan jaminan kualitas utama dalam kondisi sekarang ini (A.D. I. Kramer, J. E. Guillory, and J. T. Hancock, 2014).

Sektor kesehatan belum menangani keamanan informasi secara komprehensif. Organisasi layanan kesehatan menghadapi beragam risiko keamanan, privasi, dan kerahasiaan dan harus bertanggung jawab penuh untuk menjaga semua aspek keamanan dan kerahasiaan data dan informasi (D. Luxton, J. D. June, and J. M. Fairall, 2012). Konflik akhirnya antara berbagi data, keamanan data, dan kerahasiaan harus diatasi sejak awal dalam proses pengadaan dan pengembangan sistem dan setelah implementasi. Beberapa organisasi kesehatan telah menerapkan fitur keamanan dalam sistem informasi mereka, tetapi sebagian besar organisasi tidak memiliki aturan atau prosedur tertulis untuk penyedia layanan yang diberi wewenang untuk mengakses informasi klien, seperti kebijakan pengungkapan informasi sensitif, atau kebijakan personal (Farnan JM, et.al, 2013). Namun demikian, peraturan dan standar teknis untuk jaminan privasi dan pemeliharaan integritas data dan keamanan akses harus masuk akal, dalam hal mengakui realitas pemberian perawatan kesehatan, variabilitas lingkungan aplikasi, dan keragaman nilai etika nasional dan sistem hukum (N. Diviani, et. al, 2015).

Negara-negara berkembang secara khusus dipengaruhi oleh ekspansi cepat teknologi komunikasi interaktif semakin banyak, pemerintah, organisasi profesi, kelompok advokasi, dan pengguna di negara berkembang telah menyatakan keprihatinan tentang dampak dari kejadian tersebut. Khususnya, ada kekhawatiran besar tentang keandalan informasi pelayanan kesehatan, bentuk baru praktik kesehatan, proses periklanan dan komersial, kesesuaian konten, dan privasi, karena berkaitan dengan Internet. Lembaga multilateral atau internasional dan lembaga kerjasama teknis nasional mempromosikan penerapan aplikasi tetapi berfokus pada pengembangan infrastruktur teknologi; sedikit yang telah dilakukan mengenai konten, sumber daya manusia, evaluasi dampak, dan aspek etika dan hukum (A. Swartzendruber et al, 2018).

Peraturan dan perundang-undangan nasional dan internasional yang membahas banyak masalah yang berkaitan dengan kualitas informasi di Internet, e-commerce, dan E-Health adalah masalah yang menjadi perhatian banyak organisasi internasional saat ini. The United Nations, and particularly UNESCO, the International Telecommunications Union (ITU), the World Health Organization (WHO), the World Trade Organization (WTO), regional trade blocks (European Community, NAFTA, MERCOSUR), dan lembaga multilateral seperti World Bank and the Inter American Development Bank telah berada di garis depan inisiatif yang diarahkan untuk mempromosikan pertukaran di bidang ini (Internet Healthcare Coalition, 2000).

Ini merupakan masalah yang mendesak dan kontroversial yang harus ditangani bersama dan komprehensif oleh organisasi internasional, masyarakat ilmiah dan teknis nasional dan internasional, penyedia layanan, organisasi industri, dan kelompok kepentingan pengguna, dan tidak hanya dari sudut pandang kepentingan hukum atau komersial. Badan-badan khusus Perserikatan Bangsa-Bangsa, organisasi pemerintah, kelompok 
konsensus independen, dan penyedia layanan yang dapat dipercaya berada pada posisi yang tepat untuk mempelopori diskusi yang mengarah ke pengembangan kebijakan inovatif untuk area dan pembentukan kode etik yang berfokus pada konten, iklan, dan masalah privasi, dan deteksi penipuan yang dirancang untuk memastikan bahwa konsumen diberikan informasi kesehatan yang dapat diandalkan dan aman (Pan American Health Organization, 1999).

Disarankan agar tenaga kesehatan yang memiliki akun media sosial membuat dua akun berbeda antara akunnya sebagai pemberi edukasi kesehatan dan akun ekspresi pribadi. Pada akun yang ditujukan untuk pribadi, tenaga kesehatan perlu menolak pertemanan atau pemberian akses kepada pasien. Sedangkan, bagi akun yang dibuat untuk edukasi kesehatan, maka informasi yang layaknya terbatas pada kalangan profesional tidak boleh disampaikan pada media sosial yang tidak dapat atau minim diatur tingkat privasinya. Disarankan informasi ini disebarkan melalui jenis media sosial yang terenkripsi baik, sehingga sasaran dapat diatur secara tepat (Budd L., 2013).

Untuk menghindari masalah etik yang timbul dari penggunaan media sosial, terdapat beberapa hal yang dapat dilakukan yaitu memperketat pengaturan privasi pegawai dan pasien di layanan kesehatan. Hal tersebut perlu dilakukan untuk mengetahui siapa saja yang mengakses konten yang dibuat atau disimpan oleh tenaga kesehatan. Meskipun terdapat pengaturan privasi, dianjurkan untuk tetap waspada dengan ketidaksempurnaan sistem privasi di media sosial. Selain itu, batasan antara tenaga kesehatan dengan pasien juga perlu diperjelas. Penetapan batasan tersebut dapat dilakukan dengan menghindari hubungan non profesional secara online dengan pasien, misalnya dengan membatasi pertemanan dengan pasien di situs profesi dan menolak pertemanan dengan pasien di situs pribadi. Ketika berbagi kasus secara online, dokter hendaknya menjaga kerahasiaan pasien dengan menghilangkan identitas pasien dan tetap meminta persetujuan pasien yang bersangkutan. Perlu berhati-hati dalam memberikan opini mengenai sejawat, pegawai, fasilitas pelayanan kesehatan, atau birokrasi kesehatan. Tenaga kesehatan dituntut untuk jujur dalam berinteraksi secara online, termasuk dalam beriklan. Hanya boleh beriklan secara online untuk layanan yang sah berdasarkan informasi yang terpercaya, akurat, dan relevan (Prawiroharjo P, 2017).

Berikut ini kode etik dalam penggunaan layanan kesehatan berbasis online (E-Health) yaitu pertama, keterbukaan (penyedia layanan kesehatan diwajibkan untuk menjelaskan informasi tentang keadaan pasien. Proses keterbukaan juga harus mencakup kejelasan kepemilikan situs dan kepentingan finansial pemilik pada situs tersebut, tujuan keberadaan situs, dan hubungannya dengan pihak sponsor). Kedua, kejujuran (penyedia layanan kesehatan harus memastikan bahwa informasi, termasuk konten dan klaim terkait produk kesehatan, adalah benar dan tidak menyesatkan). Ketiga, kualitas (penyedia layanan kesehatan diwajibkan untuk menyediakan informasi yang akurat, mudah dimengerti, selalu diperbarui). Keempat, informed consent (penyedia layanan kesehatan harus menghormati hak pengguna untuk menentukan data apa saja dan bagaimana data pribadi mereka dikumpulkan, digunakan, atau dibagikan). Kelima, privacy (penyedia layanan kesehatan harus menghormati serta melindungi privasi pengguna. Memastikan keamanan layanan mereka untuk mencegah akses yang tidak sah terhadap penggunaan data pribadi). Keenam, professionalism in online health care (tenaga kesehatan yang memberikan nasihat atau perawatan medis secara online harus mematuhi kode etik masing-masing profesi. Para profesional harus menjelaskan keterbatasan 
rekomendasi terapi maupun diagnosis yang dilakukan secara online. Ketujuh, responsible partnering (sponsor atau afiliasi yang bekerjasama dengan penyedia jasa layanan kesehatan harus dapat dipercaya serta mematuhi hukum yang berlaku dan menjunjung tinggi standar etika yang sama). Kedelapan, accountability (penyedia layanan kesehatan wajib untuk menyediakan kesempatan bagi para pengguna jasa untuk memberikan umpan balik, dalam bentuk saran, kritik, mau pun pengawasan kepatuhan situs terhadap kode etik).

\section{KESIMPULAN}

Penggunaan layanan kesehatan berbasis online (E-Health) adalah masalah kesehatan masyarakat yang penting. E-Health muncul sebagai alat pengembangan diagnostik baru dan intervensi terapeutik. Adanya masalah etika yang berkaitan dengan persimpangan praktik klinik dan komunikasi online tentang pelayanan kesehatan. Hal ini memungkinkan adanya perilaku diskriminatif atau tidak etis serta tidak sesuai dengan kode etik profesi. Standar lisensi dan regulasi E-Health belum dilakukan di banyak negara. Sehingga tenaga kesehatan dituntut untuk kode etik dalam penggunaan layanan kesehatan berbasis online (E-Health).

\section{SARAN}

Pembuat kebijakan dalam hal ini Kementrian Kesehatan perlu membuat pengaturan penggunaan pelayanan kesehatan berbasis online (E-Health) agar tidak menimbulkan masalah etik dan memiliki landasan hukum yang jelas.

1. Peneliti selanjutnya diharapkan untuk dapat mengkaji lebih banyak sumber maupun referensi yang terkait dengan pelayanan kesehatan berbasis online.

2. Tenaga kesehatan diharapkan tetap harus untuk jujur dalam berinteraksi secara online. Untuk memberikan layanan kesehatan berbasis online (E-Helath) harus terpercaya, akurat, dan relevan.

\section{DAFTAR PUSTAKA}

Amelia, Fiona. (2016, September 1). Urgensi Keberadaan Kode Etik Layanan Kesehatan Online eHealth. Retrieved from http://klik dokter.com.

Stanberry BA. Legal and ethical issues in European telemedicine. European Telemedicine. 1998/99:20-25.

Mendel B. Online identity crisis. Infoworld. 1999 Oct;(18):36-37.

Smith and M. Anderson, "Social Media Use in 2018," Pew Research Center, March 1, 2018, http://www.pewinternet.org/2018/03/01/social-media-use-in-2018/.

US Department of Health and Human Services, authors. Proposed Standards for Privacy of Individually Identifiable Health Information. 1999. http://aspe.hhs.gov/admnsimp/pvcsumm.htm.

De Jong, C. R. Lucey, and R. A. Dudley, "Incorporating a New Technology While Doing No Harm, Virtually," Journal of the American Medical Association 314, no. 22 (2015): 235152. 
R. Volpe et al., “Googling a Patient," Hastings Center Report 43, no. 5 (2013): 14-15.

G. C. Bowker and S. L. Star, Sorting Things Out: Classification and Its Consequences (Cambridge, MA: MIT Press, 1999); H. K. Andreassen and K. Dyb, "Differences and Inequalities in Health: Empirical Reflections on Telemedicine and Politics," Information Communication and Society 13, no. 7 (2010): 956-75.

Clark, Capuzzi, and Harrison, "Telemedicine: Medical, Legal and Ethical Perspectives"; E. L. Egede et al., "Psychotherapy for Depression in Older Veterans via Telemedecine: Effect on Quality of Life, Satisfaction, Treatment Credibility, and Service Delivery Perception," Journal of Clinical Psychiatry 77, no. 12 (2016): 1704-11.

R. Martinson, "The Double-Edged Sword of Prison Video Visitation: Claiming to Keep Families Together While Furthering the Aims of the Prison Industrial Complex," Florida A \& M University Law Review 9, no. 1 (2013): 83-110.

L. Kvasny, "Cultural (Re)production of Digital Inequality in a US Community Technology Initiative," Information Communication and Society 9, no. 2 (2006): 160-81; Andreassen and Dyb, "Differences and Inequalities in Health."

D. Reich, "Contradictions in the Commodification of Hospital Care," American Journal of Sociology 119, no. 6 (2014): 1576-1628.

M. Simon, “HP Looking into Claim Webcams Can't See Black People," CNN, December 23, 2009.

W. Kluge, "Health Information Professionals in a Global eHealth World: Ethical and Legal Arguments for the International Certification and Accreditation of Health Information Professionals," International Journal of Medical Informatics 97 (2017): 261-65.

K. Yeung, “'Hypernudge': Big Data as a Mode of Regulation by Design," Information Communication and Society 20, no. 1 (2017): 118-36.

Grady et al., "Evidence-Based Practice for Telemental Health," Telemedicine and E-Health 17, no. 2 (2011): 131-48.

H. Kugelmass, “'Just the Type with Whom I Like to Work': Two Correspondence Field Experiments in an Online Mental Health Care Market," Society and Mental Health (March 28, 2018): 1-16, at 7, doi:10.1177/2156869318755213.

S. Char, N. H. Shah, and D. Magnus, "Implementing Machine Learning in Health CareAddressing Ethical Challenges," New England Journal of Medicine 378, no. 11 (2018): 981-83.

J. Burgess et al., "Patient Race and Physicians' Decisions to Prescribe Opioids for Chronic Low Back Pain," Social Science and Medicine 67, no.11 (2008): 1852-60; H. Kugelmass, "“Sorry, I'm Not Accepting New Patients," Journal of Health and Social Behavior 57, no. 2 (2016): 168-83.

C. A. Maher et al., "Are Health Behavior Change Interventions That Use Online Social Networks Effective? A Systematic Review," Journal of Medical Internet Research 16, no. 2 (2014): 1-16. 
M. Ananny and K. Crawford, "Seeing without Knowing: Limitations of the Transparency Ideal and Its Application to Algorithmic Accountability," New Media and Society 20 (2018): 973-89.

Eubanks, Automating Inequality; Bowker and Star, Sorting Things Out; M. Harrison, R. Koppel, and S. Bar-Lev, "Unintended Consequences of Information Technologies in Healthcare-An Interactive Sociotechnical Analysis," Journal of the American Medical Informatics Association 14 (2007): 542-49.

Lupton and Maslen, "Telemedicine and the Senses," 1564; see also P. Måseide, "Body Work in Respiratory Physiological Examinations," Sociology of Health and Illness 33, no. 2 (2011): 296-307.

A.D. I. Kramer, J. E. Guillory, and J. T. Hancock, "Experimental Evidence of Massive-Scale Emotional Contagion through Social Networks," Proceedings of the National Academy of Sciences 111, no. 24 (2014): 8788-90.

Luxton, J. D. June, and J. M. Fairall, "Social Media and Suicide: A Public Health Perspective," American Journal of Public Health 102, supplement no. 2 (2012): 195-200.

Farnan JM, Sulmasy LS, Worster BK, Chaudhry HJ, Rhyne JA, Arora VM. Online medical professionalism: Patient and public relationships: Policy statement from the American College of physicians and the federation of State Medical Boards. Ann Intern Med. 2013;158(8):620-7. doi: 10.7326/0003-4819-158-8- 201304160-00100.

N. Diviani, B. van den Putte, S. Giani, and J. C. M. van Weert, "Low Health Literacy and Evaluation of Online Health Information: A Systematic Review of the Literature," Journal of Medical Internet Research 17, no. 5 (2015): e112.

Swartzendruber et al., "Sexual and Reproductive Health Services and Related Health Information on Pregnancy Resource Center Websites: A Statewide Content Analysis," Women's Health Issues 28, no. 1 (2018): 14-20.

Internet Healthcare Coalition, authors. Tips For Health Consumers Finding Quality Health Information on the Internet. 2000. http://www.ihealthcoalition.org/content/tips.html.

Pan American Health Organization, authors. Setting Up Healthcare Services Information Systems - A Guide for Requirement Analysis, Application Specification, and Procurement. Washington(DC): Essential Drugs and Technology Program, Division of Health Systems and Services Development; 1999.

Budd L. Physician tweet thyself: A guide for integrating social media into medical practice. $B$ C Med J. 2013;55(1):38-41.

Prawiroharjo P, Libritany N. Tinjauan etika penggunaan media sosial oleh dokter. JEKI. 2017;1(1):31-4. doi: 10.26880/jeki.v1i1.7 